\title{
Pengaruh Promosi Dan Kualitas Pelayanan Terhadap Keputusan Pembelian (Studi Pada Giant Ekstra CBD Bintaro)
}

\author{
Sunanto ${ }^{*}$, Lingga Gumelar Wido Asmoro ${ }^{2}$ \\ 1,2Fakultas Ekonomi Universitas Pamulang; sunantoapt@gmail.com*
}

\begin{abstract}
Abstrak
Penelitian ini bertujuan untuk mengetahui pengaruh promosi dan kualitas pelayanan terhadap keputusan pembelian pada Giant Ekstra CBD Bintaro. Metode penelitian yang digunakan ialah metode kuantitatif dengan kuesioner. Populasinya adalah konsumen Giant Ekstra CBD Bintaro,dengan rumus slovin didapat 99 responden. Uji analisis melalui Uji Validitas, Realibilitas, Asumsi Klasik, Koefisien Korelasi Berganda, Regresi Linier Berganda, Koefisien Determinasi, dan Hipotesis. Berdasarkan hasil analisis regresi linier berganda diperoleh $Y=$ $14,446+0,062 X 1+0,547$ X2. Hasil koefisien determinasi diperoleh nilai KD sebesar o,854. Berdasarkan pengujian hipotesis yang telah dilakukan dengan menggunakan uji $F$ ) pada taraf signifikansi $5 \%$ diperoleh bahwa $F_{\text {hitung }}(15,069)>F_{\text {tabel }}(3,09)$. Hasil penelitian ini disimpulkan terdapat pengaruh yang positif dan signifikan antara Promosi dan Kualitas Pelayanan secara simultan terhadap Keputusan Pembelian pada Giant Ekstra CBD Bintaro.
\end{abstract}

Kata Kunci: Promosi; Kualitas Pelayanan; Keputusan Pembelian

\begin{abstract}
This study aims to find out the effect of promotion and quality of service on purchasing decisions at Giant Ekstra CBD Bintaro. The research method used is quantitative method with questionnaire. The population is a consumer of Giant Extra CBD Bintaro, with the formula slovin obtained 99 respondents. Test analysis through Validity Test, Eligibility, Classical Assumptions, Multiple Correlation Coefficients, Multiple Linear Regression, Determination Coefficients, and Hypotheses. Based on the calculation results of multiple linear regression analysis obtained $Y=$ $14,446+0.062 X 1+0.547 X 2$. The result of determinant coefficient obtained KD value of 0.854. Based on hypothesis testing that has been done using $F$ test) at the level of significance of 5\% obtained that $F_{-}$hitung $(15,069)>F_{-}$tabel(3.09). The results of this study concluded that there is a positive and significant influence between the Promotion and Quality of Service simultaneously on the Purchase Decision at Giant Extra CBD Bintaro.
\end{abstract}

Keywords: Promotion; Quality of Service; Decision Making

*) Korespondensi penulis 


\section{PENDAHULUAN}

Giant Ekstra CBD Bintaro mengalami penurunan minat beli konsumen dilihat dari penurunan pada tahun 2019 dibanding tahun sebelumnya. Pendugaan mengarah pada kualitas layanan, seperti, antrian di kasir dan barang kosong. Pendugaan lain mengacu pada aspek promosi, seperti matriks promosi yang belum optimal, seperti penggunaan media sosial, print ad, POP yang belum optimal. Fenomena fenoema ini menarik perhatian penulis untuk meneliti pengaruh promosi dan kualitas pelayanan secara simultan terhadap keputusan pembelian pada Giant Ekstra CBD Bintaro.

\section{Konsep Promosi}

Menurut Cannon Perreault \& McCarthy (2014:69) promosi (promotion) adalah "mengkomunikasikan informasi antara penjual dan pembeli potensial atau orang lain dalam saluran untuk mempengaruhi sikap dan prilaku". Sementara Fandy Tjiptono (2019:399) menyatakan pada hakekatnya promosi adalah "bentuk komunikasi pemasaran, yang dimaksud dengan komunikasi pemasaran adalah akatifitas yang berusaha menyebarkan informasi, mempengaruhi, membujuk, dan mengingatkan pasar sasaran atas perusahaan dan produk agar tersedia menerima, membeli, dan loyal pada produk yang ditawarkan perusahaan yang bersangkutan. Berikut variabel tersebut menurut Tjiptono, Greogorius \& Dadi (2019:399):

a. Pariklanan

Periklanan adalah segala bentuk penyajian dan promosi bukan pribadi mengenai gagasan, barang atau jasa yang dibayarka oleh sponsor tertentu. Periklanan merupakan salah satu dari empat alat pennting yang digunakan suatu perusahaan untuk melancarkan komunikasi persuasif terhadap pembeli dan masyarakat. Komunikasi persuasif ini ditunjukan untuk menciptakan pertukaran yang memuaskan.

b. Promosi Penjualan

Promosi penjualan merupakan salah satu kegiatan promosi, kegiatan promosi penjualan antara lain : peragaan (demonstrasi), pertunjukan atau pameran.

c. Hubungan Masyarakat Hubungan masyarakat adalah fungsi manajemen yang mengevaluasi sikap publik, mengidentifikasi kebijakan dan prosedur organisasi demi kepentingan publik dan melaksanakan program aksi dan komunikasi untuk membentuk pemahaman dan ekspektasi publik agar mendapatkan respon positif.

d. Penjualan Tatap Muka

Penjualan tatap muka adalah interaksi tatap muka antar penjual dengan satu atau lebih calon pembeli unuk melakukan persentasi pengenalan produk, menjawab pertanyaan sehingga membentuk pemahaman pelanggan terhadap produk agar mereka ingin mencoba dan membelinya.

e. Pemasaran Langsung

Pemasaran langsung adalah sistem pemasaran yang bersifat interakktif, yang menggunakan berbagai media komunikasi untuk meningkatkan respon langsung yang bersifat spesifik dan terukur.

\section{Konsep Kualitas Pelayanan}

Definisi menurut Kotler (2014:129) adalah "keseluruhan fitur dan karakteristik produk dan jasa yang berpengaruh pada kemempuannya untuk memuaskan kebutuhan yang dinyatakan atau tersirat" .Menurut Fandy Tjiptono (2019:59) mengemukakan bahwa "kualitas pelayanan adalah tingkat keunggulan yang diharapkan dan pengendalian atas tingkat keunggulan tersebut untuk memenuhi keinginan pelanggan". 
Menurut Fandy Tjiptono (2019:77) dimensi yang dapat dijadikan acuan untuk menilai kualitas pelyanan antara lain meliputi :

a. Keandalan (Reliability), berkaitan dengan kemampuan perusahaan untuk menyampaikan layanan yang dijanjikan secara akurat sejak pertama kali.

b. Daya Tanggap (Responsiveness), berkenaan dengan kesediaan dan kemampuan penyedia layanan para konsumen dan mrespon permintaan mereka dengan segera.

c. Bukti Fisik (Tangible), berkaitan dengan penampilan fisik, fasilitas layanan, peralatan/perlengkapan, sumber daya manusia dan materi komunikasi perusahaan.

d. Empati (Empaty), berhubungan dengan pemahaman perusahaan mengenai masalah para konsumennya dan bertindak demi kepentingan konsumen, sertta perhatian secara personal kepada para konsumen.

e. Jaminan (Assurance), berkenaan dengan pengetahuan dan kesopanan karyawan serta kemampuan mereka dalam menumbuhkan rasa percaya dan keyakinan pada konsumen.

\section{Konsep Keputusan Pembelian}

Menurut Kotler dan Keller (2015:173) keputusan pembelian konsumen adalah "proses psikologis dasar yang dapat memainkan peran penting dalam memahami bagaimana konsumen benar-benar membuat keputusan pembelian mereka". Perusahaan yang cerdas berusaha untuk memahami proses keputusan pembelian pelanggan secara penuh yaitu semua pengalaman mereka dalam pembelajaran, memilih, menggunakan dan bahkan menyingkirkan produk. Indikator Keputusan Pembelian

Kotler dan Keller (2015:479) mengemukakan proses keputusan pembelian yang dilakukan pembelian yaitu :

a. Pemilihan Produk
Konsumen menentukan produk mana yang akan dibeli, setiap merek memiliki nilai baginya. Perusahaan harus mengetahui produk seperti apa yang diinginkan konsumen.

b. Pemilihan Merek

Konsumen harus menentukan merek mana yang akan dibeli, setiap merek memiliki perbedaan-perbedaan tersendiri. Dalam hal ini perusahaan harus mengetahui bagaimana konsumen memilih sebuah merek.

c. Pemilihan Saluran Pembelian

Konsumen harus mengambil keputusan tentang penyalur mana yang akan dikunjungi. Setiap konsumen berbedabeda dalam hal menentukan penyalur, dapat dikarenakan faktor lokasi yang dekat, harga yang murah, persediaan barang yang lengkap, kenyamanan berbelanja dan keluasaan tempat.

d. Keputusan Pembelian

Dalam tahap evaluasi, para konsumen membentuk referensi atas merek yang ada didalam kumpulan pilihan. Konsumen juga dapat membentuk niat untuk membeli merk yang paling disukai.

e. Jumlah Pembelian

Konsumen dapat mengambil keputusan tentang seberapa banyak produk yang akan dibelinya pada suatu saat. Pembelian yang dilakukan mungkin lebih dari satu jenis produk. Dalam hal ini perusahaan harus mempersiapkan banyaknya produk sesuai dengan keinginan yang berbeda-beda dari pembeli.

\section{Penelitian Terdahulu}

Yan, J., Tian, K., Heravi, S., \& Morgan, P. (2017). The vices and virtues of consumption choices: price promotion and consumer decision making. Hasil penelitian terdapat pengaruh yang signifikan antara promosi dan keputusan konsumen.

Sunanto (2015): Pengaruh Faktor Individu, Lingkungan Konsumen dan 
Strategi Pemasaran Terhadap Keputusan Konsumen Pada Apotik Sunfarma Tangerang Selatan. Hasil penelitian terdapat pengaruh yang sifnifikan antara faktor invidu, lingkungan konsumen dan strategi pemasaran terhadap keputusan pembelian.

Cheah, J.-H., Ting, H., Cham, T. H., \& Memon, M. A. (2019). The effect of selfie promotion and celebrity endorsed advertisement on decision-making processes. Hasil penelitian menyebutkan bahwa promotion berpengaruh terhadap proses keputusan pelanggan

Wulandari, D., \& Subagio, A. (2015). Consumer Decision Making in Conventional Banks and Islamic Bank based on Quality of Service Perception. Hasil penelitian menyebutkan kaulitas layanan terkait erat dengan keputusan konsumen.

Dari beberapa penelitian terdahulu didapat pemahaman bahwa promosi, kualitas pelayanan berhubungan dengan keputusan pembelian konsumen.

\section{Kerangka Berpikir}

Menurut Sugiyono (2015:93) mengemukakan bahwa kerangka berpikir merupakan model konseptual tentang bagaimana teori berhubungan dengan berbagai faktor yang telah diidentifikasi sebagai masalah yang penting. Kerangka berpikir teoritis yang disajikan menjelaskan bahwa ada tiga variabel yang akan diteliti yaitu: promosi dan kualitas pelayanan merupakan variabel dependen (X), sedangkan untuk variabel independen (Y) yaitu keputusan pembelian. Dari kedua variabel tersebut akan diteliti apakah terdapat pengaruh positif dan signifikan antara kualitas pelayanan terhadap keutusan pembelian pada Giant Ekstra CBD Bintaro. Variabel yang digunakan dalam suatu penelitian dapat dilihat dalam gambar 1 di bawah ini.

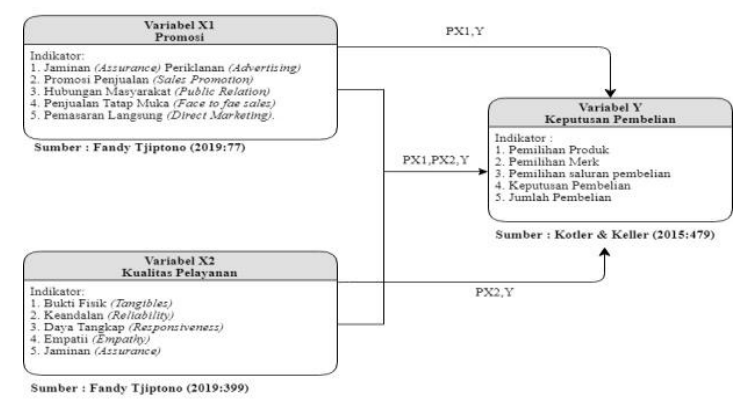

Gambar 1. Kerangka Berfikir

\section{Hipotesis}

Hipotesis yang akan dibuktikan yaitu:

$H_{3}$ : Terdapat pengaruh signifikan promosi dan kualitas pelayanan terhadap keputusan pembelian pada Giant Ekstra CBD Bintaro.

\section{METODE}

Metode penelitian bersifa deskriptip kualitatif menggunakan variabel bebas promosi dan kualitas pelayanan sebagai variabel terikat yaitu keputusan pembelian (variabel Y). Populasi penelitian ini adalah konsumen Giant Ekstra CBD Bintaro yang berjumlah 168.072 konsumen, jumlah tersebut didapat dari 3 bulan terakhir sebelum penelitian yaitu pada bulan Maret sampai dengan Mei 2020. Sedangkan jumlah sampel berjumlah 99 responden (Slovin). Teknik sampling dengan menggunakan convenience sampling. Teknik pengumpulan data menggunakan data primer melalui kusioner yang dibagikan kepada responden dengan menggunakan skala linkert.

\section{HASIL dan PEMBAHASAN \\ Hasil Analisis Deskriptif Variabel Promosi(X1)}

Tanggapam responden sangat beragam, responden yang menjawab sangat setuju dan setuju sebesar $(27,88 \%$ $+58,09 \%)=86,97 \%$ dengan perolehan rata-rata skor 4,13 termasuk pada skala 3,40 - 4,19 dengan kriteria baik. 


\section{Variabel Kualitas Pelayanan (X2)}

Tanggapan responden sangat beragam, responden yang menjawab sangat setuju dan setuju sebesar $(29,49 \%$ $+58,90 \%)=88,39 \%$ dengan perolehan rata-rata skor 4,15 termasuk pada skala 3,40 - 4,19 dengan kriteria baik.

\section{Variabel Keputusan Pembelian $(\mathrm{Y})$}

Tanggapam responden sangat beragam, responden yang menjawab sangat setuju dan setuju sebesar $(23,13 \%$ $+58,10 \%)=81,23 \%$ dengan perolehan rata-rata skor 3,97 termasuk pada skala 3,40 - 4,19 dengan kriteria baik.

\section{Uji Validitas}

Adapun kriteria dalam pngujian ini adalah sebagai berikut: dengan taraf signifikansi $5 \%$ dan derajat kebebasan (df) $=\mathrm{N}-2=99-2=97$ sehingga didapat nilai $r_{\text {tabel }}$ sebesar 0,197. Kriteria validitas instrumen atau kuesioner dapat ditentukan apabila $r_{\text {hitung }}>r_{\text {tabel }}=$ valid, Apabila $r_{\text {hitung }}<r_{\text {tabel }}=$ tidak valid. Hasil uji validitas untuk seluruh instrumen $>1,97$, sehingga seluruh instrumen dalam variabel promosi, kualitas layanan, dan keputusan pembelian dinyatakan valid.

\section{Uji Realibilitas}

Hasil uji reliabilitas untuk seluruh instrumen $>0,6$, sehingga seluruh variabel promosi, kualitas layanan, dan keputusan pembelian dinyatakan valid:

\section{Uji Asumsi Klasik}

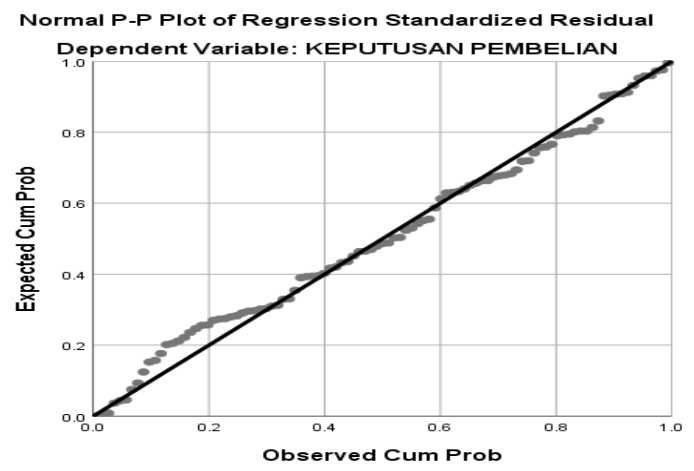

Grafik 2. Grafik Normal Probability Plot
Dari tampilan grafik normal Probability Plot-nya terlihat titik-titik menyebar berhimpit mendekati garis diagonal, serta penyebarannya mengikuti garis diagonal. Sehingga dinyatakan model regresi dalam penelitian ini memenuhi asumsi normalitas.

\section{Uji Multikolinearitas}

Tabel 1. Hasil Uji Multikolinieritas

\begin{tabular}{|c|l|c|c|}
\multicolumn{2}{|c|}{ Model } & \multicolumn{2}{|c|}{ Collinearity Statistics } \\
\cline { 3 - 4 } 1 & Tolerance & VIF \\
\cline { 2 - 4 } & (Constant) & & \\
\cline { 2 - 4 } & PROMOSI & 0.713 & 1.403 \\
\cline { 2 - 4 } & $\begin{array}{c}\text { KUALITAS } \\
\text { PELAYANAN }\end{array}$ & 0.713 & 1.403 \\
\hline
\end{tabular}

a. Dependent Variable: KEPUTUSAN PEMBELIAN

Nilai tolerance variabel promosi dan kualitas pelayanan yakni o,713 lebih besar dari 0,10 dengan mmasing-masing nilai VIF 1,403 lebih kecil dari 10,00. Disimpulkan bahwa tidak terjadi multikolinearitas pada penelitian ini.

\section{Uji Heteroskedastisitas}

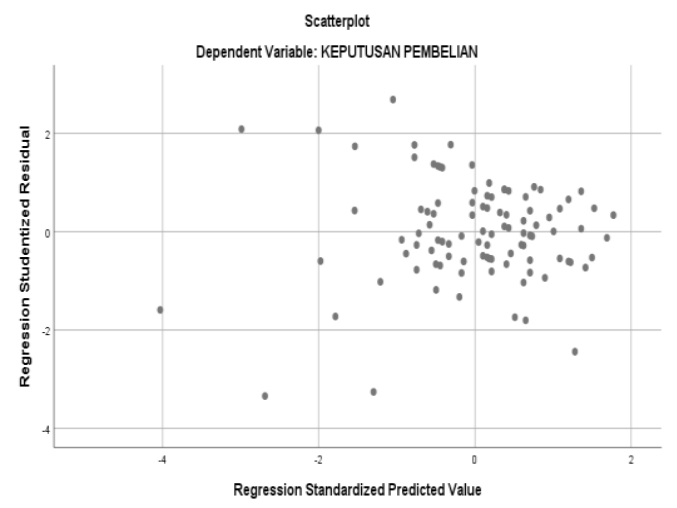

Gambar 3. Uji Heteroskedastisitas

Dari gambar uji heteroskedastisitas terlihat bahwa titik-titik menyebar secara acak tidak membentuk suatu pola yang jelas. Disimpulkan tidak terjadi heteroskedastisitas pada model regresi.

\section{Analisis Regresi Linier Berganda}

Hasil analisis regresi pengaruh variabel promosi dan kualitas pelayanan terhadap keputusan pembelian pada Giant 
Extra CBD Bintaro ditunjukkan pada tabel berikut:

\begin{tabular}{|c|c|c|c|c|c|}
\hline \multicolumn{6}{|c|}{$\begin{array}{l}\text { Tabel 2. Hasil Analisis } \\
\text { Regresi Linier Berganda }\end{array}$} \\
\hline & \multirow{2}{*}{ Model } & \multicolumn{2}{|c|}{$\begin{array}{l}\text { Unstandardized } \\
\text { Coefficients }\end{array}$} & \multirow{2}{*}{$\mathrm{t}$} & \multirow{2}{*}{ Sig. } \\
\hline & & B & $\begin{array}{l}\text { Std. } \\
\text { Error }\end{array}$ & & \\
\hline \multirow{3}{*}{1} & (Constant) & 14.446 & 4.964 & 2.91 & 0.004 \\
\hline & PROMOSI & 0.062 & 0.122 & 0.504 & 0.615 \\
\hline & $\begin{array}{l}\text { KUALITAS } \\
\text { PELAYANAN }\end{array}$ & 0.547 & 0.126 & 4.343 & $\mathrm{O}$ \\
\hline
\end{tabular}

a. Dependent Variable: KEPUTUSAN PEMBELIAN

Dari tabel 2 diperoleh persamaan regresi linier berganda $Y=14,446+0,062 \mathrm{X1}+$ o,547 X2. Persamaan ini mempunyai arti:

Koefisien constant (Konstanta) sebesar 14,446 menyatakan bahwa jika variabel promosi dan kualitas pelayanan nilainya o (nol), maka keputusan pembelian nilainya adalah 14,446 .

Koefisien regresi $\mathrm{X} 1$ atau untuk variabel promosi adalah sebesar positif o,062 bermakna bahwa setiap bertambahnya kualitas pelayanan sebesar 1\% maka keputusan pembelian akan mengalami peningkatan sebesar 0,062.

Koefisien regresi X2 atau variabel kualitas pelayanan adalah sebesar positif o,547 bermakna bahwa setiap bertambahnya promosi sebesar $1 \%$ maka keputusan pembelian akan mengalami peningkatan sebesar 0,547

\section{Koefisien Determinasi}

Koefisien determinasi digunakan untuk melihat kemampuan variabel independen dalam menerangkan variabel dependen, dimana nilai Adjusted R Square yang mendekati satu maka variabel independen memeberikan hampir semua informasi yang dibutuhkan untuk memprediksi variasi variabel dependen.

Tabel 3. Hasil Uji Koefisien Determinasi Model Summary

\begin{tabular}{|c|c|c|c|c|} 
Model & $\mathrm{R}$ & $\begin{array}{c}\mathrm{R} \\
\text { Square }\end{array}$ & $\begin{array}{c}\text { Adjusted } \\
\text { R Square }\end{array}$ & $\begin{array}{c}\text { Std. Error } \\
\text { of the } \\
\text { Estimate }\end{array}$ \\
\hline 1 & $.924^{\mathrm{a}}$ & 0.854 & 0.845 & 1.227 \\
\hline
\end{tabular}

Dari hasil perhitungan diperoleh $\mathrm{R}$ square 0,854 artinya variabel promosi dan kualitas pelayanan terhadap keputusan pembelian adalah sebesar $85.4 \%$ dan sisanya $14,6 \%$ dipengaruhi oleh faktorfaktor lain yang tidak dimasukkan dalam model penelitian ini.

\section{Uji Simultan (Uji F)}

Tabel 4. Promosi dan Kualitas Pelayanan Terhadap Keputusan Pembelian

ANOVAa

\begin{tabular}{|c|c|c|c|c|c|c|}
\hline \multicolumn{2}{|c|}{ Model } & $\begin{array}{l}\text { Sum of } \\
\text { Squares }\end{array}$ & $\mathrm{df}$ & $\begin{array}{c}\text { Mean } \\
\text { Square }\end{array}$ & $\mathrm{F}$ & Sig. \\
\hline \multirow{3}{*}{1} & $\begin{array}{l}\text { Regre } \\
\text { ssion }\end{array}$ & 485.3 & 2 & 242.65 & 15.069 & $.000^{b}$ \\
\hline & $\begin{array}{l}\text { Residu } \\
\text { al }\end{array}$ & 1545.9 & 96 & 16.103 & & \\
\hline & Total & 2031.2 & 98 & & & \\
\hline
\end{tabular}

a. Dependent Variable: KEPUTUSAN PEMBELIAN

b. Predictors: (Constant), PROMOSI, KUALITAS PELAYANAN

Berdasarkan tabel diperoleh nilai $F_{\text {hitung }}(15.069)>F_{\text {hitung }}(3,09)$ dengan nilai signifikan $0,000<0,05$ ), yang berarti variabel promosi dan kualitas pelayanan berpengaruh signifikan terhadap keputusan pembelian.

\section{Pembahasan}

Hasil uji uji hipotesis (Uji F) menunjukan bahwa promosi (X1) dan kualitas pelayanan (X2) berpengaruh positif dan signifikan terhadap keputusan pembelian ( $\mathrm{Y}$ ) dengan konstribusi $85,4 \%$ perubahan terjadi pada keputusan pembelian dapat dijelaskan oleh variabel independen (promosi dan kualitas pelayanan). Hasil ini mendukung teori dari Kotler (2013) bahwa promosi dan kualitas layanan berhubungan erat dengan keputusan pembelian. Penelitian ini juga sejalan dengan Yan, J., dkk. (2017) dan Cheah, dkk (2019) bahwa promosi berpengaruh signifikan terhadap keputusan pembelian konsumen. 


\section{SIMPULAN}

Berdasarkan hasil dan pembahasan dapat disimpulkan bahwa promosi dan kualitas pelayanan berpengaruh positif dan signifikan terhadap keputusan pembelian di Giant Ekstra CBD Bintaro.

Implikasi hasil penelitian ini adalah perusahaan dalam memprediksi pengambilan keputusan konsumen harus memperhatikan aspek promosi dan kualitas layanan.

\section{DAFTAR PUSTAKA}

Apriwati Sholihat. (2019). Pengaruh Promosi Penjualan Dan Kualitas Pelayanan Terhadap Keputusan Pembelian Di Krema Koffie. Journal of Chemical Information and Modeling.

Buchory Herry Acmad dan Saladin Djaslim. (2015). Pengaruh People , Physical Evidence, Product, Promotion , Price Dan Place Terhadap Tingkat Kunjungan Di Kafe Coffee Cozies Surabaya. Jurnal Manajemen Pemasaran Petra.

Cheah, J.-H., Ting, H., Cham, T. H., \& Memon, M. A. (2019). The effect of selfie promotion and celebrity endorsed advertisement on decisionmaking processes. Internet Research. doi:10.1108/intr-12-20170530

Djaslim, Saladin, 2002. (2017). Manajemen Pemasaran: Analisis, Pelaksanaan, dan Pengendalian, Linda Karya, Bandung. Journal of Chemical InformationalModeling.

Kotler dan Keller. (2017). Manajemen Pemasaran, Edisi 12, Jilid 1, PT. Indeks,. Jakarta. e-Jurnal Riset Manajemen.

Kottler, P., \& Armstrong, G. (2014). Prinsip-Prinsip Pemasaran (Edisi ke12. Jilid ke-1). Jakarta: Erlangga.

Rangkuti, F. (2013). Teknik Membedah Kasus Bisnis Analisis SWOT Cara Perhitungan Bobot, Rating, dan
OCAI. PT. Gramedia Pustaka Utama. Jakarta.

Sugiyono. (2015). Metode Penelitian dan Pengembangan Pendekatan Kualitatif, Kuantitatif, dan R\&D,Bandung: Alfabeta.

Sunanto. (2015). Analisis Pengaruh Faktor Individu, Lingkungan Konsumen, dan Strategi pemasar-an Terhadap Keputusan Pembelian Pada Apotik Sunfarma -Tangerang Selatan. Kreatif 3(1). Jurnal Ilmiah Prodi Manajemen.

Swastha, Basu, I. (2014). Manajemen Pemasaran Modern. Yogyakarta: Liberty

Tjiptono, F. (2019). Strategi Pemasaran Prinsip \& Penerapan. Yogyakarta: Andi.

Wulandari, D., \& Subagio, A. 2015. Consumer Decision Making in Conventional Banks and Islamic Bank based on Quality of Service Perception. Procedia-Social and Behavioral Sciences, 211, 471475 doi:10.1016/j.sbspro.2015.11.062

Yan, J., Tian, K., Heravi, S., \& Morgan, P. (2017). The vices and virtues of consumption choices: price promotion and consumer decision making. Marketing Letters, 28(3), 461-475. doi:10.1007/s11002-017-9421-x 